\title{
CONF-980632--
}

\section{Spatial and Temporal Variations in the Atmospheric Aerosol Optical Depth at the ARM CART Site}

\author{
98-RAC.03P (A143)
}

Terra M. Nash and Meng-Dawn Cheng*

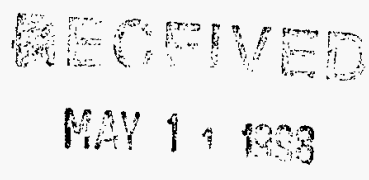

Oak Ridge National Laboratory, Environmental Sciences Division, P. O. Box 2008 M Oak Ridge, TN, USA.

\section{ABSTRACT}

In an effort to better characterize the inputs to radiative transfer models and research-grade global climate simulation models (GCMs) the columnar aerosol loading, measured as the aerosol optical depth (AOD), has been computed for five facilities within the Atmospheric Radiation

Measurement (ARM) Southern Great Plains (SGP) Cloud and Radiation Testbed (CART) Site. Characterization of the AOD reported here show clear evidence that the spatial and temporal gradient exists at a much finer linear scale than those of the CART site. The annual variations of median AOD are on the order of 0.30 at all five facilities. The Spearman correlation and varimaxrotated PCA indicated the AOD values vary consistently across the CART site. The Northwest corner facility (EF-1) was the single facility that behaved differently from the rest. This sub-GCM grid variation can not be ignored if the model it to be used to accurately predict future climate change.

\section{INTRODUCTION}

The issue of global warming had recently held the attention of world leaders and scientists with the signing of the Kyoto Accord in December of 1997. In the accord many nations agreed to reduce anthorpogenic emissions of six "greenhouse gases" to the atmosphere because of global warming predictions by Global Climate Models (GCMs). GCMs divide the Earth's surface into large grids for calculations. GCMs assume that a grid or sub-grid process is homogenous, and one average number is used by the models to represent the process state. Many of the input parameters to the GCMs, like cloud cover, ozone concentration, water vapor, and aerosol loading, vary on a scale that is much smaller than the current grids. More complex models, working on a more detailed spatial scale, are needed to better predict the long-term changes of the global climate ${ }^{1}$. While researches are needed to improve these models, accurate measurements are imperative to the models. The Atmospheric Radiation Measurement (ARM) program, sponsored by the Department of Energy (DOE), is committed to collect, document, and archive data critical to this research over a long time period (20 years).

Aerosols play a critical role in affecting cloud formation and altering atmospheric radiative transfer ${ }^{2}$. These are two key processes, among others, affecting surface temperature and precipitation. The aerosol optical depth (AOD) has been shown to be one of the most important parameters in many radiative transfer models. Literature ${ }^{3}$ indicates variation of $13.5 \mathrm{~W} / \mathrm{m}^{2}$ in the direct-normal solar irradiance would result from a change in the AOD value of 0.01 . The sensitivity of atmosphere radiative calculations to other model parameters such as precipitable water and ozone was found to besmaller by an order of magnitude when compared to aerosols under clear-sky

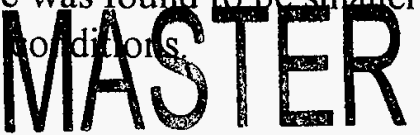

DISTRIBUTION OF THIS DOCUMENT IS UNLLMITED M
"The subnitted manuscript has been authorized by a contractor of the U.S. Government under contract No. DE-AC05-960R22464. Accordingly, the U.S. Government retains a non-exclusive, royalty-free license to publish or reproduce the published form of this contribution, or allow others to do so, for U.S. Government purposes." 


\section{DISCLAIMER}

This report was prepared as an account of work sponsored by an agency of the United States Government. Neither the United States Government nor any agency thereof, nor any of their employees, make any warranty, express or implied, or assumes any legal liability or responsibility for the accuracy, completeness, or usefulness of any information, apparatus, product, or process disclosed, or represents that its use would not infringe privately owned rights. Reference herein to any specific commercial product, process, or service by trade name, trademark, manufacturer, or otherwise does not necessarily constitute or imply its endorsement, recommendation, or favoring by the United States Government or any agency thereof. The views and opinions of authors expressed herein do not necessarily state or reflect those of the United States Government or any agency thereof. 
The influence of aerosols to climate prediction is one area of interest in ARM's ongoing multiyear experiments. To improve GCMs and parameterize aerosol processes the spatial and temporal variations of AOD has to be characterized thoroughly. The atmospheric column aerosol loading (as represented by AOD) used in radiative transfer calculation has typically been taken as a constant for a GCM grid ${ }^{4}$. To explore the spatial and temporal variation of AOD and its impacts on the GCM predictions, surface radiometric data from five facilities at the ARM Southern Great Plains (SGP) Cloud and Radiation Testbed (CART) site from 1 May 1996 to 31 April 1997 were retrieved from the ARM archive 5 located at the Oak Ridge National Laboratory (ORNL) in Oak Ridge, Tennessee. The AOD at five facilities at the SGP site were then calculated and analyzed using the Least Median Squares-Langley (LMS-Langley) technique developed at ORNL ${ }^{6}$. (The LMS-Langley technique is fully described in the Theory and Methodology section.)

\section{DESCRIPTION OF SITE AND DATA}

The CART site shown in Figure 1 was designed to observe and provide needed data for the improvement of GCM prediction and cloud parameterization. The site is about the size of a GCM grid at the mid-latitude, approximately $250 \mathrm{~km}$ (East to West) by $350 \mathrm{~km}$ (North to South) and is centered at Lamont, Oklahoma. The site covers the area that is between 99.3 to $95.5^{\circ} \mathrm{W}$ latitude and 38.3 to $34.8^{\circ} \mathrm{N}$ longitude and lies anywhere from 217 to 664 meters above sea level. The main land use at the site is agricultural, either cropland or pasture. No significantly large pollution sources are nearby; thus it is believed to be representative of a "clean" continental site. Hundreds of meteorological instruments were installed at the CART site. More than 4 million geophysical variables have been collected each day since the early 1990's; the sampling intervals range from seconds to minutes ${ }^{7}$.

We focused on five extended facilities (EF) that housed the Multi-Filter Rotating Shadowband Radiometers (MFRSR). These facilities are denoted as, EF-1, EF-3, EF-13, EF-20, \& EF-24 on the figure. They are located at the four corners (EF-1, EF-3, EF-20 and EF-24) and the center (EF-13) of the CART site for maximum spatial coverage.

The MFRSR was phased into use in 1994 to gather shortwave spectral solar radiation data at the CART site. The MFRSR, as shown in Figure 2, measures diffused horizontal and total horizontal solar irradiance at 20-second intervals. The MFRSR takes a series of four measurements in each pass. The first is with the shadowband at nadir and measures total horizontal solar irradiance. The next three measurements are with the band at $9^{\circ}$ to one side of the sun, then directly blocking the sun and then $9^{\circ}$ to the other side. The diffused horizontal irradiance is measured when the shadowband is blocking the sun, but because the band is larger than the solar disk, corrections must be made. The two measurements at $9^{\circ}$ are taken to correct for the extra width of the shadowband. The direct normal narrowband irradiance is the difference between the total and corrected diffused solar irradiance ${ }^{8}$. The central wavelengths for these narrowband measurements are $415,500,608,664$, and 860 nano-meters $(\mathrm{nm})$ and they have a $10 \mathrm{~nm}$ full width at half maximum.. In this analysis the direct normal narrowband irradiance of these five wavelengths were used for the AOD calculations. Figure 3 shows an example of the direct normal-narrowband irradiance on a cloudless day at five wavelengths, with the maximum at local noon and minimums at sunrise and sunset. The AOD was derived for these five (5) wavelengths from the MFRSR 
data using the LMS-Langley technique ${ }^{6}$. The results to be presented in this paper are from the $500 \mathrm{~nm}$ channel only.

\section{THEORY AND METHODOLOGY}

The AOD is a fraction of the total optical depth (TOD). The TOD can be attributed to the solar irradiance that is scattered or absorbed by all material in the MFRSR viewpath as it is passing through the Earth's atmosphere. The majority of the materials in this view path include aerosols, air molecules, ozone, water vapor, and clouds. When calculating the clear-sky AOD, corrections are required for the Rayleigh scattering by air molecules, ozone absorption, and water vapor absorption. At the wavelengths mentioned in this paper absorption of light by water vapor is insignificant; thus the correction for water absorption was not performed. Since we were only interested in the clear-sky effects of aerosols on radiative transfer the cloudy time periods were removed after the LMS regression was performed. The TOD is the linear sum of the AOD, Rayleigh scattering, and ozone absorption ${ }^{2}$.

Equation 1. The components of Total Optical Depth (TOD)

$\mathrm{TOD}=\mathrm{AOD}+\mathrm{ROD}+\mathrm{O} 3 \mathrm{OD}$

Where:

TOD $=$ Total Optical Depth (unitless)

$\mathrm{AOD}=$ Aerosol Optical Depth (unitless)

ROD $=$ Rayleigh Optical Depth (unitless)

O3OD = Ozone Optical Depth (unitless)

TOD was computed by the Langley method described by Cheng and Kopet ${ }^{6}$ that used the robust LMS regression technique. The Langley Law describes the attenuation of solar irradiance as it passes through the atmosphere.

Equation 2. The Langley Law for one wavelength

$I=I_{0} * e^{-\tau m}$

Where:

$I=$ Spectral irradiance at the ground surface $\left(\mathrm{W} \mathrm{m}^{-2} \mathrm{~nm}^{-1}\right)$

$I o=$ Spectral irradiance at the top of the atmosphere $\left(\mathrm{W} \mathrm{m}^{-2} \mathrm{~nm}^{-1}\right)$

$m=$ Air mass (unitless)

$\tau=$ total optical depth (unitless)

$I$ is the direct normal irradiance measurement from the MFRSR. The airmass was determined from the relative position between the Earth and the Sun; i.e. the day of the year and time of day (or angle to the sun) and is calculated from the equation derived by Kasten ${ }^{9}$. Io and $\tau$ were computed for AM and PM periods that have an airmass between 1.5 and 6 when performing a LMS regression analysis on the following equation. 
Equation 3. The Natural Log of the Langley Law

$\ln (\mathrm{I})=\ln (\mathrm{Io})-\tau m$

This form allows a linear regression to be performed. The LMS minimizes the median squared residual from the regression analysis ${ }^{10}$. Once the minimal median squared residual was found, the intercept of the line from that iteration was determined to be the $\ln (I o)$. After the regression, standardized residuals that were greater than 2.5 were removed from the data. Data points with residuals less than 2.5 were considered good by LMS for the subsequent AOD calculations. Then the Io was substituted back into Equation 3 to further derive the instantaneous aerosol optical depth for each 20 -second data point from the data that was not removed by the standardized residual filter.

Rayleigh molecular scattering and ozone absorption need to be corrected for AOD. There are many empirical equations available from the literature for calculating the ROD. Equation 4 was chosen so that comparisons could be made with the work of others ${ }^{11}$.

Equation 4. Rayleigh Optical Depth equation used ${ }^{12,13}$.

$\mathrm{ROD}=0.008569 * \lambda^{-4}\left(1+0.0113 * \lambda^{-2}+0.00013 * \lambda^{-4}\right)$

Where:

$\lambda=$ wavelength in $\mathrm{nm}$

ROD $=$ Rayleigh Optical Depth, unitless

This equation is for sea level so correction is needed for the change in atmospheric pressure at each facility by multiplying by the actual barometric pressure and dividing by the pressure at standard conditions (101.325 mbars). The actual barometric pressure at 1 meter height was taken at each ARM facility by the Surface Meteorological Observation System (SMOS) ${ }^{14}$ was used. The ROD is generally large at smaller wavelengths and decreases as the wavelength increases.

The ozone concentration was measured by an ozone spectrophotometer at the NOAA/CMDL (National Oceanic and Atmospheric Administration / Climate Monitoring \& Diagnostics Laboratory) facility in Nashville, TN. The atmospheric ozone is measured in Dobson Units $(\mathrm{DU})^{15}$. These values were used as they were readily available and there was a good agreement with the column ozone abundance estimated at the CART site by other methods ${ }^{16}$. To calculate O3OD, the ozone absorption cross-section from Shettle and Anderson ${ }^{17}$ was used. The O3OD has a peak absorption in the Chappuis bands at about $600 \mathrm{~nm}$, so it affects the TOD at $608 \mathrm{~nm}$ most. Once the TOD, ROD and O3OD are all calculated the AOD was found using Equation 1.

\section{RESULTS AND DISCUSSION}

Using the AODs calculated, the monthly trends at the five facilities were compared. The AOD at the five facilities were also compared to one another for study of spatial variations. The results shown in this paper are given for the wavelength of $500 \mathrm{~nm}$. Smaller wavelengths have an increasing ROD component and the larger wavelengths have increased ozone interference's. Therefore, the $500 \mathrm{~nm}$ channel was considered to be a useful wavelength for AOD retrieval ${ }^{18}$. 


\section{Annual Variation Across the Site}

The monthly median AOD values were plotted for each facility in Figure 4 to show the temporal variations of AOD across the CART site. There was a minimum in the AOD values in December with the smallest median AOD of 0.019 occurring at EF-1. The individual AOD values were very low in winter (December through February), in the range of 0.017 to 0.127 . The highest median AOD values are found during the summer months (June through August). The median summer AODs range from 0.130 to 0.298 . The pattern of annual AOD variations found at the CART site was similar to those in the studies by Smirnov et. al. ${ }^{19}$ and Devara et al. ${ }^{20}$ taken at other sites. Both studies show minimum AOD values in the winter months and maximum values in the summer. The inner-quartile range $\left(75^{\text {th }}\right.$ percentile $-25^{\text {th }}$ percentile) (IQR) of a month also varied on an annual basis. The winter IQR was much smaller than those in the summer showing less variability in the colder months. The winter monthly IQRs range from 0.009 to 0.093 and from 0.062 to 0.278 in the summer. The work by Smirnov et. al. in rural Canada found monthly averaged AOD values that were of the same magnitude as the ones found at the CART site. While the annual pattern in Figure 4 was similar to Devara et al., their AOD values were much larger than those reported here. That was a result from the urban aerosols in Pune, India.

\section{Daily Variation}

Figure 5 shows the daily AOD values for March, 1997 at EF-13 with the median and the $25^{\text {th }}$ to $75^{\text {th }}$ percentiles represented by the box, with the whiskers being 1.5 times the quartile box. The days that were missing did not meet the LMS-Langley criteria. The 20-second AOD values in March, 1997 ranged from a minimum of 0.022 to the maximum of 0.221 with a median of 0.079 . The daily variations in Figure 5 show that the magnitude of variations (maximum to minimum) within a single day for AOD is significant to cause an impact on radiative energy $\operatorname{transfer}^{2}$. Figure 5 also shows that the AOD can vary substantially from day to day. The AOD on March $21^{\text {st }}$, 1997, was highly variable from 0.07 to 0.18 (maximum to minimum), while on the day before it was only varied from 0.17 to 0.18 . This was a ten-fold change of AOD variation in two days.

The 20-second AOD values for the morning of October 26, 1996 were shown in Figure 6. The median AOD was 0.128 with the IQR from 0.125 to 0.130 . At about 9:30 local time there was a local AOD minimum of 0.117. In less that one hour the AOD increased to above 0.140 and then fell to below 0.117 . This AOD variation again was substantial.

\section{Spatial Variation}

For an initial assessment of spatial similarity of AOD values at the five facilities, the pair-wise Spearman correlation coefficients were calculated. The Spearman coefficients found in Table 1, ranged from 0.49 (EF-1 vs. EF-13) to 0.84 (EF-13 vs. EF-20). The correlation coefficients show that the EF-1 was not correlated with the other four facilities. EF-1 is located at the northwest corner of the CART site (see Figure 1). To verify that the EF-1 was not correlated with the other facilities a Varimax Principal Components analysis (PCA) was performed. The eigenvalues after a varimax rotation indicated that the first two factors were significant and that they explained $89 \%$ of the AOD variation within the CART site. The next largest eigenfactor explained only an additional $8 \%$ of the total variance. The factor loadings as seen in Table 2 indicate that the first factor describes the variation at EF-3, 13,20 and 24. The second factor was contributed by a single facility, EF-1. The second factor showed that the EF-1 facility was unique. Both the 
Spearman correlation coefficients and PCA show that the variations at EF-1 were dis-similar to the other facilities at the CART site.

\section{CONCLUSIONS AND RECOMMENDATIONS}

Characterization of the AOD reported here show clear evidence that the spatial and temporal gradient exists at a much finer linear scale than those of the CART site. The annual variations of median AOD are on the order of 0.30 at all five facilities. The Spearman correlation and varimaxrotated PCA indicated the AOD values vary consistently across the CART site. The Northwest corner facility (EF-1) was the single facility that behaved differently from the rest. These results suggest the aerosol found at the CART site were originated from long-distance sources. The results further suggest the site-wide fluctuations was possibly a reflection of the synoptic meteorological influence.

In short, we find that optical depths of aerosols varied consistently across a site of 250 by 350 $\mathrm{km}^{2}$; however, the spatial and temporal variations (as in the magnitude of change) were substantial within the site. This sub-GCM grid variation can not be ignored if the model it to be used to accurately predict future climate change. Improved parameterization is needed to incorporate aerosol processes into the next generation GCMs.

\section{ACKNOWLEDGMENTS}

This research was partially funded by the US Department of Energy ARM program. This report is the Oak Ridge National Laboratory Environmental Sciences Division Publication Number 4758. Data were obtained from the Atmospheric Radiation Measurement Program sponsored by the U.S. Department of Energy Research, Office of Health and Environmental Research, Environmental Sciences Division. The authors wish to thank the Archive staff, especially Debbie Shepherd, for their excellent assistance retrieving the massive MFRSF data files. MDC also acknowledges the Archive for computing support and data storage management. Oak Ridge National Laboratory, managed by Lockheed Martin Energy Research Corp. For the U.S. Department of Energy under contract number DE-AC05-960R22464.

\section{REFERENCES}

1. Smaglik, P. Scientist 1998. 12-I 1

2. Atmospheric Aerosols, Twomey, S., Elsevier Scientific Publishing: Amsterdam, 1977.

3. Halthore, R.N.; Schwartz, S.E.; Michalsky, J.J.; Anderson, G.P.; Farrare, R.A.; Holben, B.N.; Ten Brink, H.M. J. of Geophys. Res. 1997. 102-D25. 29,991-30,002

4. Penner, J.E..; Charlson, R.J.; Hales, J.M.; Laulainen, N.S.; Leifer, R.; Novakov, T.; Ogren, J.; Radke, L.F.; Schwartz, S.E.; Travis, L. Bulletin of the Amer. Met. Soc. 1994. 75(3). 375-400

5. Internet Web Page Uniform Resource Locator (URL) - http://www.archive.arm.gov/

6. Cheng, M.D.; Kopetz, E.S. J. Aerosol Sci., in review.

7. Cheng, M.D., Hubbs, C.; McCord, R. EOS /American Geophys. Union. 1996. 493

8. Harrison, L.; Michalsky, J.; Berndt, J. Appl. Optics. 1994, 33-22, 5118-5125

9. Kasten, F. Arch. Meterol. Geophys. Bioklimatol. 1965. B 14. 206-223 
10. Robust Regression and Outlier Detection, Rousseeuw, P.J.; Leroy, A.M., John Wiley \& Sons: NewYork, 1987.

11. Harrison, L.C.; Michalsky, J.J. Appl. Optics. 1994, 33-22 5126-5132

12. Hansen, J.E.; Travis, L.D. Space Sci. Rev. 1974, 16, 527

13. Teillet, P.M. Appl. Optics. 1990, 29-13, 1897-1900

14. Internet Web Page URL - http://www.arm.gov/docs/instruments/static/smos.html

15. Internet Web Page URL - http://www.cmdl.noaa.gov/dobson

16. Michalsky, J.J.; Liljegren, J.C.; Harrison, L.C. J. of Geophys. Res. 1995, 100-D12, 25,99526,003

17. Shettle, E.P.; Anderson, S. Proceedings of the $17^{\text {th }}$ Annual Review Conference on Atmospheric Transmission Models, June 1994, 335-345

18. Michalsky, J.J., State University of New York, Albany, personal communication, 1998

19. Smirnov, A.; O'Neill, N.T.; Royer, A.; Tarussov, A. J. of Geophys. Res. 1996, 101-D14 $19,299-19,318$

20. Devara, P.C.S.; Pandithurai, G.; Rja, R.E.; Sharma, S. J. Aerosol Sci. 1996, 27-4, 621-632 
Figure 1. Map of ARM SGP CART Site with Facilities of Interest Circled (Scale: $50 \mathrm{~km} / \mathrm{in}$ )

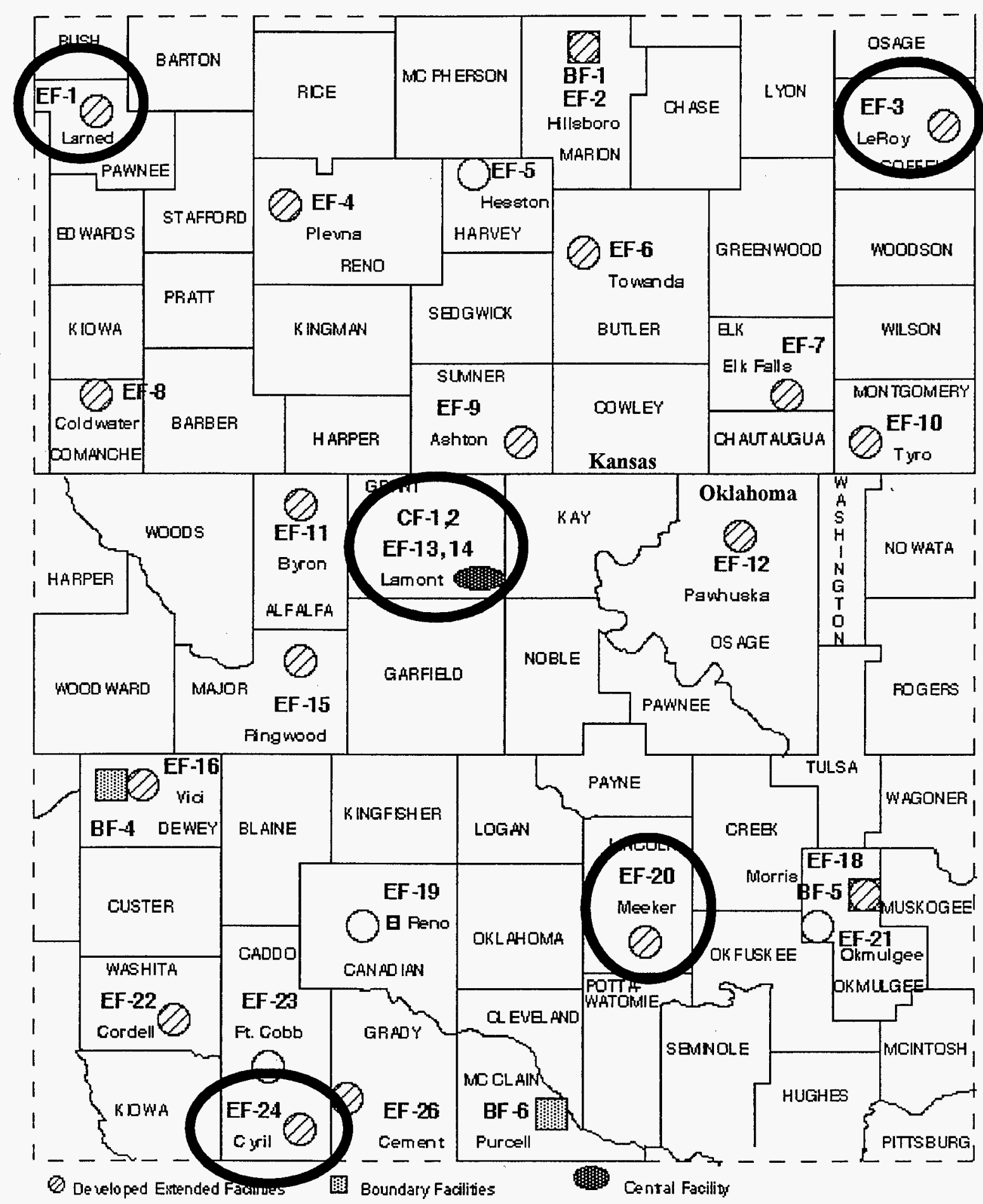


Figure 2. The Multi-Filter Rotating Shadowband Radiometer

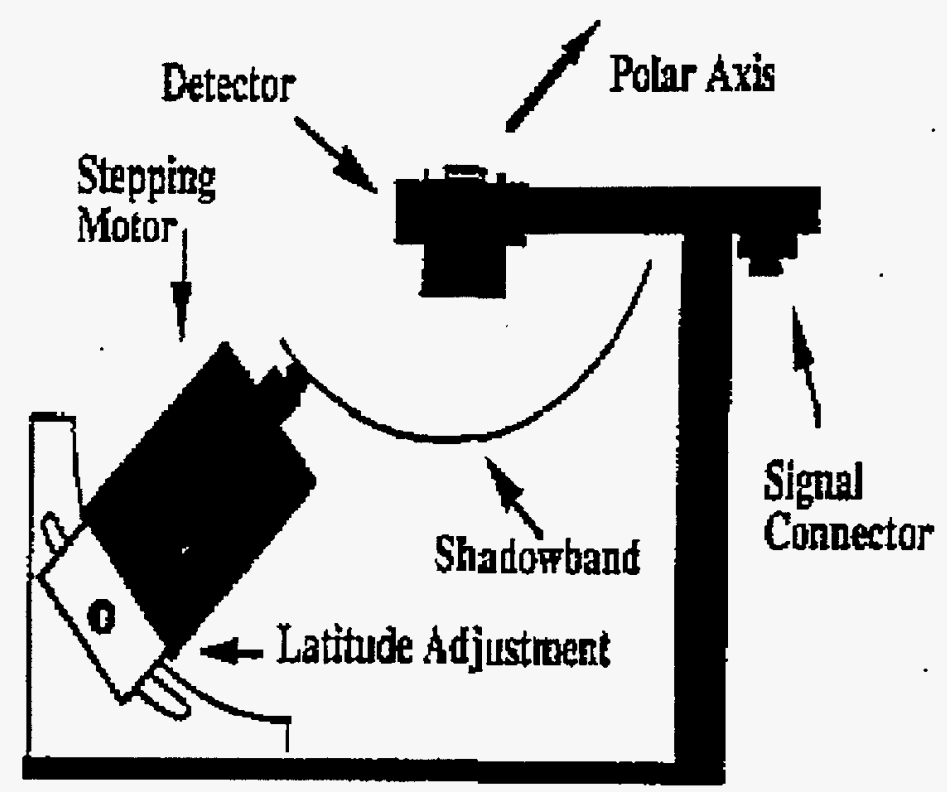

Source:

http://www.arm.gov/docs/documents/technical/conf_9303/2670a_10/michalsky_3/figure_1.html 
Figure 3. Example of the Direct Irradiance Measurements by MFRSR at Five Wavelengths at the Central Facility, E13, on a Cloudless Day.

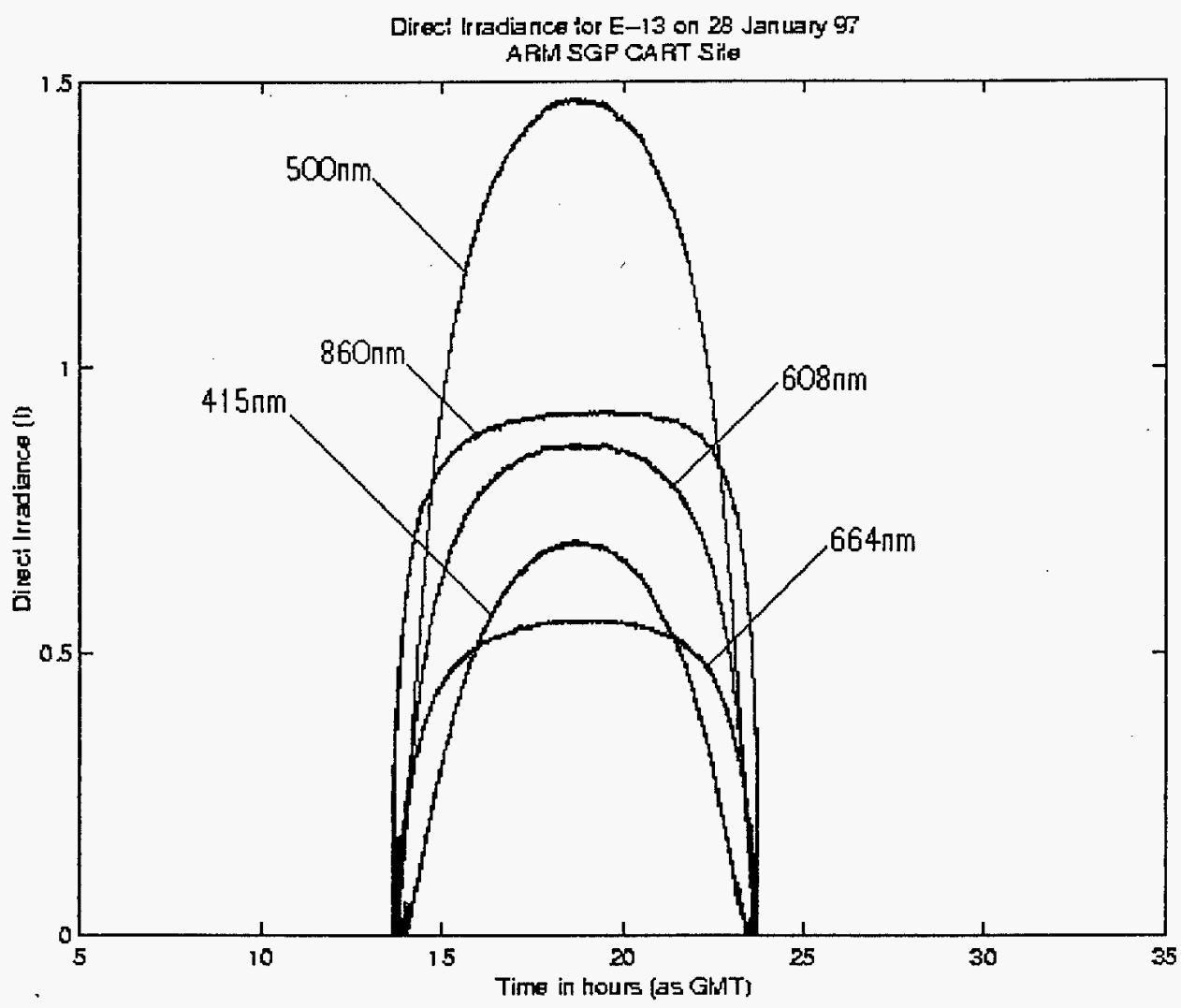

The unit for the irradiance was $\mathrm{W} \mathrm{m}^{-2} \mathrm{~nm}^{-1}$. Time axis was the Greenwich Mean Time that was approximately 6.5 hours ahead of the local time in January. The max. occurs at about 19$6.5=12.5$ hour. 
Figure 4. Monthly Median AOD for the Five Extended Facilities at the ARM SGP CART site for 1 May 96 to 30 April 97

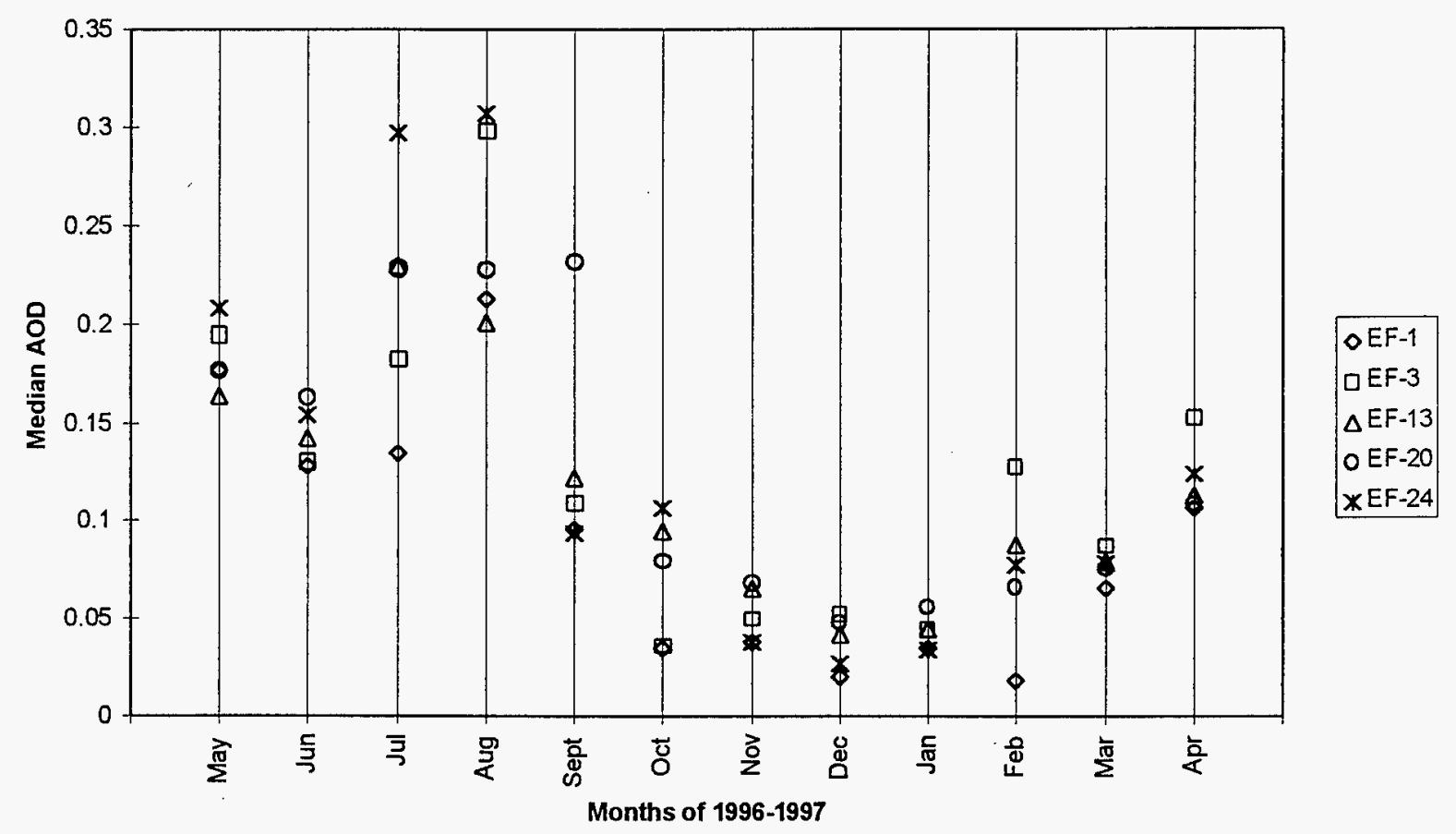


Figure5. Daily Variation of 500nm AOD for March 1997 at the Extended Facility 13

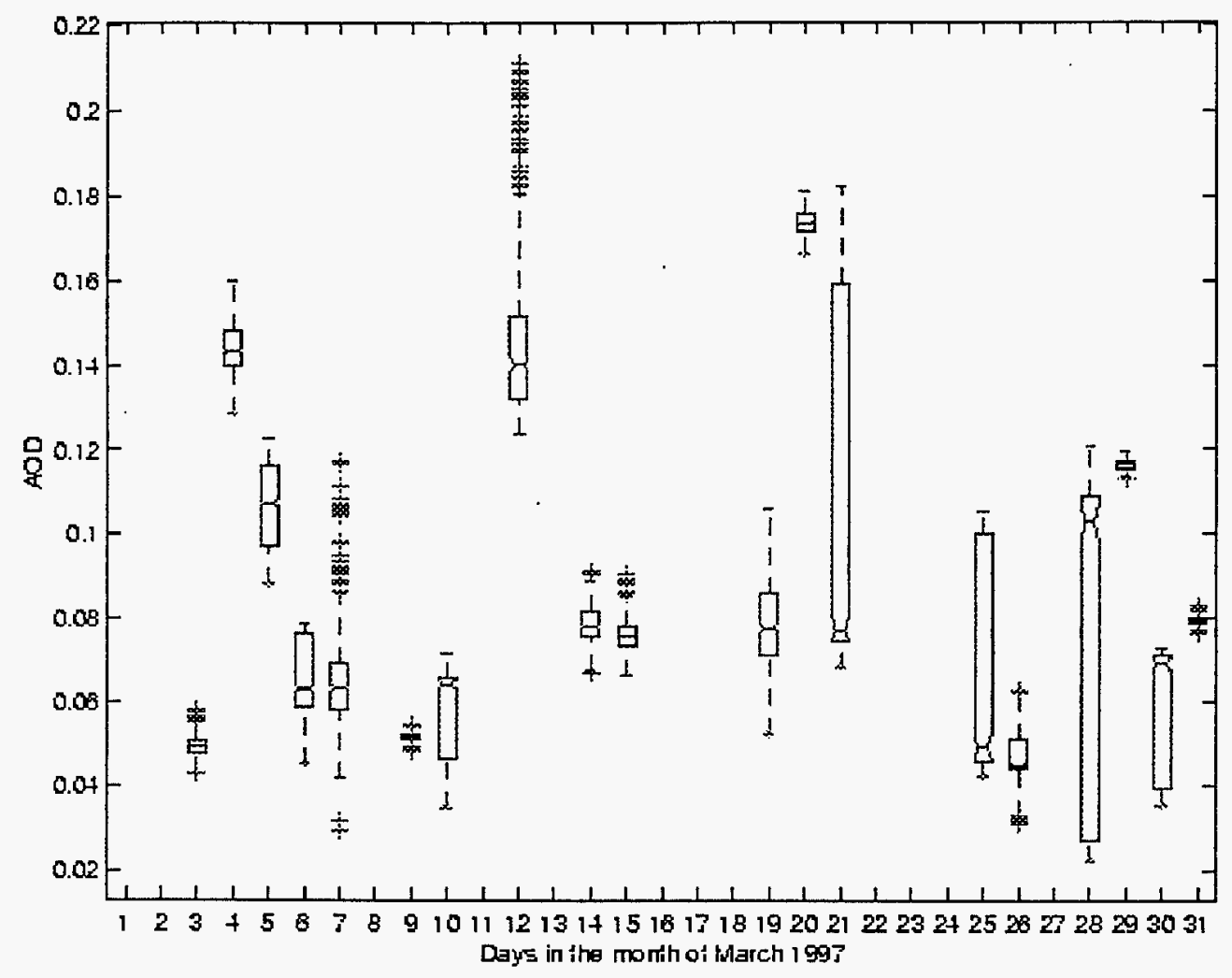


Figure 6. AOD on Morning of October 26, 1996 at the Extended Facility 13

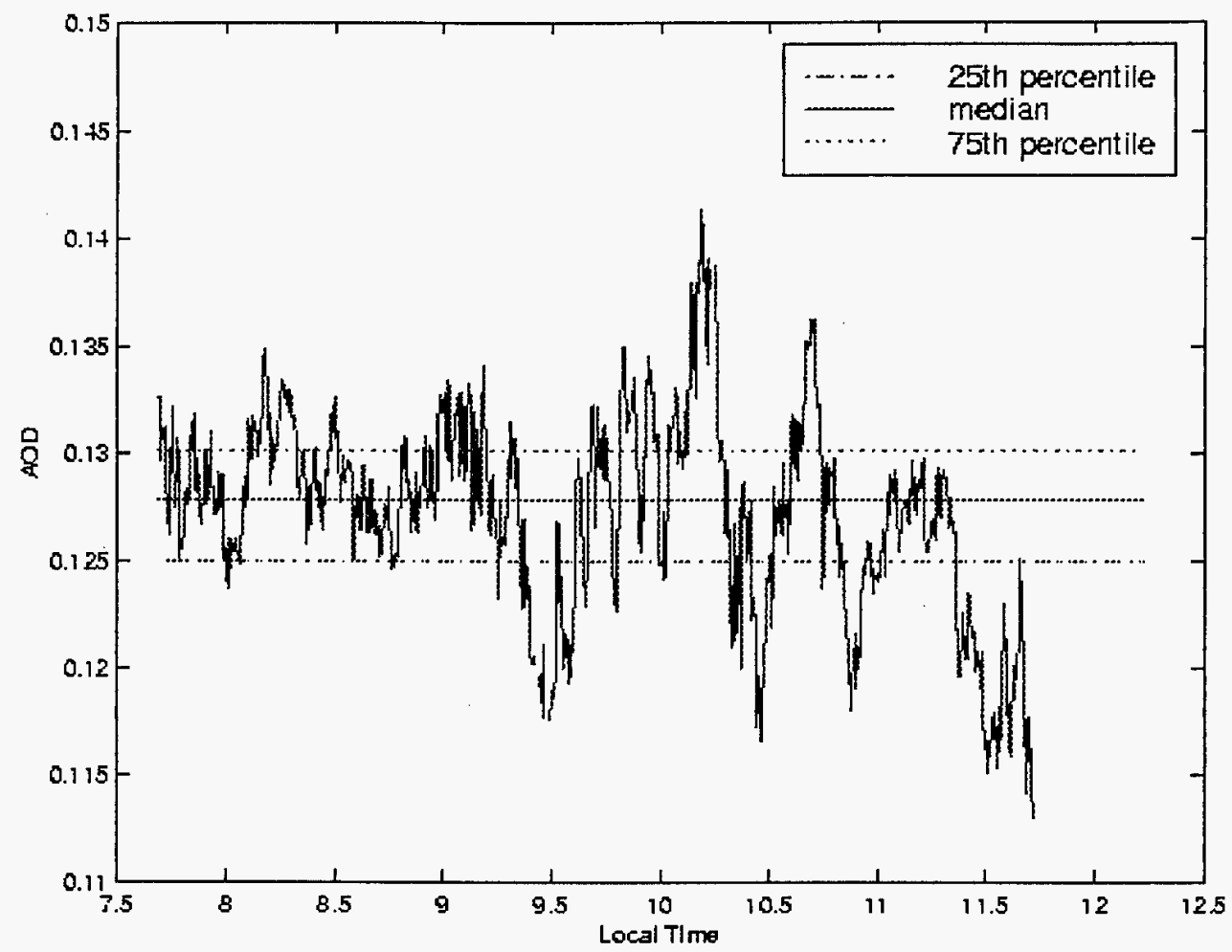


Table 1. Spearman Correlations for Extended Facilities

\begin{tabular}{c|c|c|c|c|c} 
& EF-1 & EF-3 & EF-13 & EF-20 & EF-24 \\
\hline EF-1 & 1.0 & & & & \\
\hline EF-3 & 0.66 & 1.0 & & & \\
\hline EF-13 & 0.50 & 0.81 & 1.0 & & \\
\hline EF-20 & 0.57 & 0.81 & 0.84 & 1.0 & \\
\hline EF-24 & 0.62 & 0.77 & 0.73 & 0.79 & 1.0
\end{tabular}

Table 2. Factor Loadings after Varimax PCA Rotation

\begin{tabular}{c|c|c} 
Facilities & Factor 1 & Factor 2 \\
\hline EF-1 & -0.29 & $\mathbf{- 0 . 9 5}$ \\
\hline EF-3 & $\mathbf{- 0 . 9 7}$ & -0.21 \\
\hline EF-13 & $\mathbf{- 0 . 7 5}$ & -0.44 \\
\hline EF-20 & $\mathbf{- 0 . 8 7}$ & -0.42 \\
\hline EF-24 & $\mathbf{- 0 . 8 2}$ & -0.39
\end{tabular}




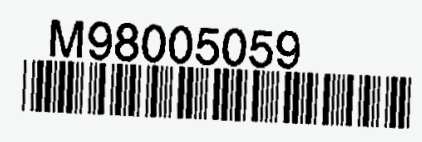

Report Number (14) ORNL/CP-96847

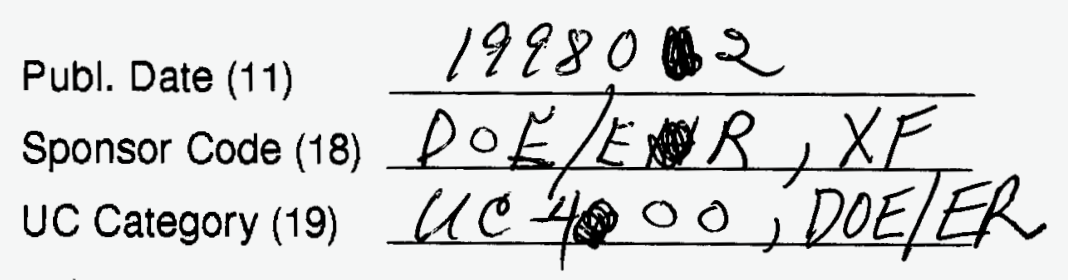

\section{7} DIIC QDATIIY INOPECTED 1 